\title{
COPING WITH UNCERTAINTY IN PUBLIC HEALTH: THE USE OF HEURISTICS
}

\author{
Louise Cummings \\ Nottingham Trent University, UK
}

\section{Introduction}

The observation that experts and lay people use cognitive shortcuts or heuristics to arrive at judgements about complex problems is certainly not new. But what is new is the finding that a group of reasoning strategies, which have been maligned by philosophers and logicians alike, have demonstrable value in helping members of the public come to judgement about public health problems. These problems, which span food safety crises, immunization scares and risks associated with exposure to environmental toxins, presuppose knowledge and expertise which falls outside of the epistemic and technical competence of most members of the public. Notwithstanding the complexity of these problems, they are not perceived by lay people to be wholly unintelligible or incomprehensible. This short communication reports on the findings of a questionnaire-based investigation into the use of these reasoning strategies by 879 members of the public. The results reveal a rational competence on the part of lay people which has been hitherto unexamined, and which may be usefully exploited in all aspects of public health work.

This study extends earlier work which demonstrated extensive use of these same reasoning strategies by scientists who sat on expert advisory committees during the UK's BSE epidemic. ${ }^{1}$ These committees, which included the Southwood Working Party and the Spongiform Encephalopathy Advisory Committee, were charged with making assessments of the risks that BSE posed to human health. An almost consistent feature of the work of these committees was that scientists found themselves in the position of making judgements about the human health risks of BSE within very short time frames and often in advance of having access to the results of experimental and epidemiological studies. The epistemic context within which these scientists operated was thus one of pervasive uncertainty. Against this epistemic backdrop, it was demonstrated that scientists made use of a group of reasoning strategies to help guide them in their risk assessments. These strategies, it was argued, took the form of arguments which have occupied a somewhat inauspicious place in the long history of logic. 
Known as the informal fallacies, these arguments include such names as the argument from ignorance, question-begging or circular argument, and analogical argument. In Cummings (2010), it was argued that although these arguments have historically been viewed as forms of weak or bad reasoning, they actually have significant epistemic merits at the outset of a scientific inquiry. Specifically, these arguments were shown to facilitate the reasoning of BSE scientists by bridging gaps in their knowledge during risk assessments. To the extent that these arguments enabled scientists to circumvent uncertainty related to the lack of knowledge of this new disease, they functioned as effective mental shortcuts or cognitive heuristics. ${ }^{2}$ It was with the aim of establishing if these same arguments are also used by lay people, and for a similar purpose, that the current study was undertaken.

\section{Informal fallacies as cognitive heuristics}

In demonstration of the types of reasoning strategies examined in the current study, consider the following arguments:

\section{Argument A:}

There is no evidence that scrapie in sheep is transmissible to humans.

Therefore, scrapie in sheep is not transmissible to humans.

\section{Argument B:}

BSE in cattle is similar to scrapie in sheep.

Scrapie in sheep is not transmissible to humans.

Therefore, BSE in cattle will not be transmissible to humans.

Argument $A$ is a classic argument from ignorance. In this informal fallacy, an arguer reasons from a lack of evidence or knowledge that $\mathrm{P}$ is the case to the conclusion that $\mathrm{P}$ is not the case (where P stands for a proposition, in this case 'scrapie in sheep is transmissible to humans'). Similarly, an arguer may also reason from a lack of evidence or knowledge that $\mathrm{P}$ is not the case to the conclusion that $\mathrm{P}$ is the case. For much of the history of logic, logicians have tended to rail against the argument from ignorance on the grounds that a lack of evidence or knowledge should not be taken as proof that something is or is not the case. It is only in more recent logical analyses that philosophers have attempted to characterise the conditions under 
which this argument is rationally warranted. ${ }^{3,4}$ If a knowledge base in a particular domain is closed (epistemic closure) and has been exhaustively searched, and a proposition is found not to be contained within that base, then there are strong grounds for claiming that the proposition is false. Just such was the case in argument $A$. This argument was used by Brown et al. (1987) at the conclusion of a 15-year epidemiological investigation of CJD in France and following a review of world literature into the disease. ${ }^{5}$ Given that the knowledge base on CJD was closed after this lengthy period of investigation, and had been exhaustively searched by Brown and his colleagues, there were strong grounds indeed for claiming that if there was no evidence that scrapie was transmissible to humans then it was most likely not to be transmissible. This conclusion was particularly important as it was largely contemporaneous with the emergence of BSE in British cattle in 1986. Having recognized its strongly warranted status, scientists employed this conclusion extensively in BSE risk assessments, as can be seen from its inclusion as a premise in argument B. B is an analogical argument, another informal fallacy which was investigated in this study. This argument consists in an analogical premise that expresses a similarity or likeness between two entities $A$ and $B$. A second premise states that $A$ has property $\mathrm{P}$, from which the reasoner derives the conclusion that $\mathrm{B}$ also has property P. The remaining two arguments investigated involve a reasoner arguing from a premise that is identical to the conclusion-to-be-proved (circular argument) and arguing from the expertise of an authority to the truth of the pronouncements of that authority (the argument from authority).

The significance of these arguments is that when applied in certain contexts of use, they are not only valid forms of reasoning but they can also be facilitative of the wider scientific inquiries of which they are a part. This facilitation can take many forms such as warranting decisions to take public health measures (the introduction of the human Specified Bovine Offal ban in the case of BSE) or to implement a certain program of research. It is this important function of these arguments that warrants their description as cognitive heuristics. For the most part, BSE scientists were successful at recognising the contexts under which these arguments were valid (although, as it was argued in Cummings (2010), they also made some frightful errors in this regard). A question of some import that is addressed by the current study is whether the lay person is similarly equipped to recognise these contexts. 


\section{Public health reasoning and the lay person}

The principal aim of this study was to establish if members of the public could identify the epistemic and logical conditions under which four informal fallacies were more or less rationally warranted during deliberations about public health problems. A total of 879 subjects participated in the study. These subjects included 292 men and 587 women aged between 18 and 65 years. Subjects were of diverse educational and ethnic backgrounds (see Table 1). They were enrolled in the study during a series of formal recruitment activities which were conducted in public venues (e.g. health clubs, foyers of hospitals) across the East Midlands region of England. The fallacies selected for study were the argument from ignorance, circular argument, analogical argument and the argument from authority. These fallacies were presented to subjects in paragraph-length scenarios in an anonymous questionnaire which could be completed in 30-40 minutes. Each subject received eight scenarios which included examples of all four argument types. Of the four questions that followed each passage, two required short responses and were designed to test subjects' understanding of explicit information in the passage. The aim of these questions was to create the impression on the part of subjects that they were engaging in a reading comprehension task rather than a reasoning experiment. A third question aimed to establish if subjects had drawn a particular inference. This was typically indicated by a 'yes' or 'no' response, or a response that required subjects to circle one of the following: valid; moderately valid; not valid at all. A fourth question was open-ended and encouraged subjects to expand on the logical grounds for an inference. Logical and epistemic conditions (e.g. epistemic closure) were systematically varied across the 24 scenarios in the study (see Table 2 ). All scenarios were scrutinised by two public health consultants in advance of the study and were judged to have a high degree of plausibility.

Quantitative data from the current study were analysed using the Statistical Package for the Social Sciences (SPSS for Windows Version 18.0). Because the data in this study is categorical, non-parametric statistical tests were used. SPSS provides a Pearson chi-square test for

significance testing. Detailed results are reported elsewhere. ${ }^{6}$ However, it should be noted that several significant Pearson chi-square values were obtained. For example, in relation to the argument from ignorance, there was a significant difference $(p<0.05)$ in the number of respondents who accepted ignorance inferences under conditions of complete epistemic 
closure and exhaustive search in comparison with conditions in which there was incomplete epistemic closure of a knowledge base and limited search of the base. Alongside other findings of this type, it is clear that certain epistemic and logical conditions hold rational sway with lay subjects in much the same way that they did for expert scientists during the BSE epidemic. As well as providing support for the claim that lay subjects are able to discern the conditions under which informal fallacies are more or less rationally warranted during public health deliberations, these findings have potentially valuable practical applications to public health. The findings of this study suggest that we can be reasonably confident about the prospects of developing this rational capacity on the part of the public through a range of educational efforts: people can be trained to be critical thinkers. This confidence is in stark contrast to the view of 'many researchers [who] think that attempts to improve decisionmaking through education [...] lie somewhere between over-optimistic and hopeless' ${ }^{7}$ A fully developed rational capacity can then be exploited by public health agencies to achieve greater compliance of populations with a range of health measures, and better public understanding of vital health communications.

\begin{tabular}{|c|l|}
\hline \multirow{2}{*}{ AGE } & \multicolumn{1}{|c|}{ SUBJECT CHARACTERISTICS } \\
\hline GENDER & $\begin{array}{l}\text { Average: } 43.8 \text { years } \\
\text { Range: } 18-65 \text { years } \\
\text { Male: } 292 \text { subjects } \\
\text { Female: } 587 \text { subjects }\end{array}$ \\
\hline & $\begin{array}{l}\text { University level: } 589 \text { subjects } \\
\text { Secondary school level: } 290 \text { subjects }\end{array}$ \\
\hline
\end{tabular}




\begin{tabular}{|l|l|}
\hline \multirow{2}{*}{ ETHNICITY } & White British: 789 subjects \\
& White Irish: 30 subjects \\
Asian or British Asian Indian: 15 subjects \\
Asian or British Asian Pakistani: 4 subjects \\
Black or Black British Caribbean: 3 subjects \\
Black or Black British African: 3 subjects \\
Mixed: White and Black Caribbean: 1 subject \\
Mixed: White and Black African: 1 subject \\
Mixed: White and Asian: 1 subject \\
Other: 32 subjects
\end{tabular}

Table 1: Subject characteristics

\section{Description of public health scenario}

\section{ARGUMENT FROM AUTHORITY}

1 Genuine, impartial expertise; actual scenario:

Pronouncements on BSE by the Spongiform Encephalopathy Advisory Committee

2 Genuine, impartial expertise; non-actual scenario:

Use of chemicals in food production

3 Genuine, partial expertise; actual scenario:

Aspirin use and Reye's syndrome in children

4 Genuine, partial expertise; non-actual scenario: 


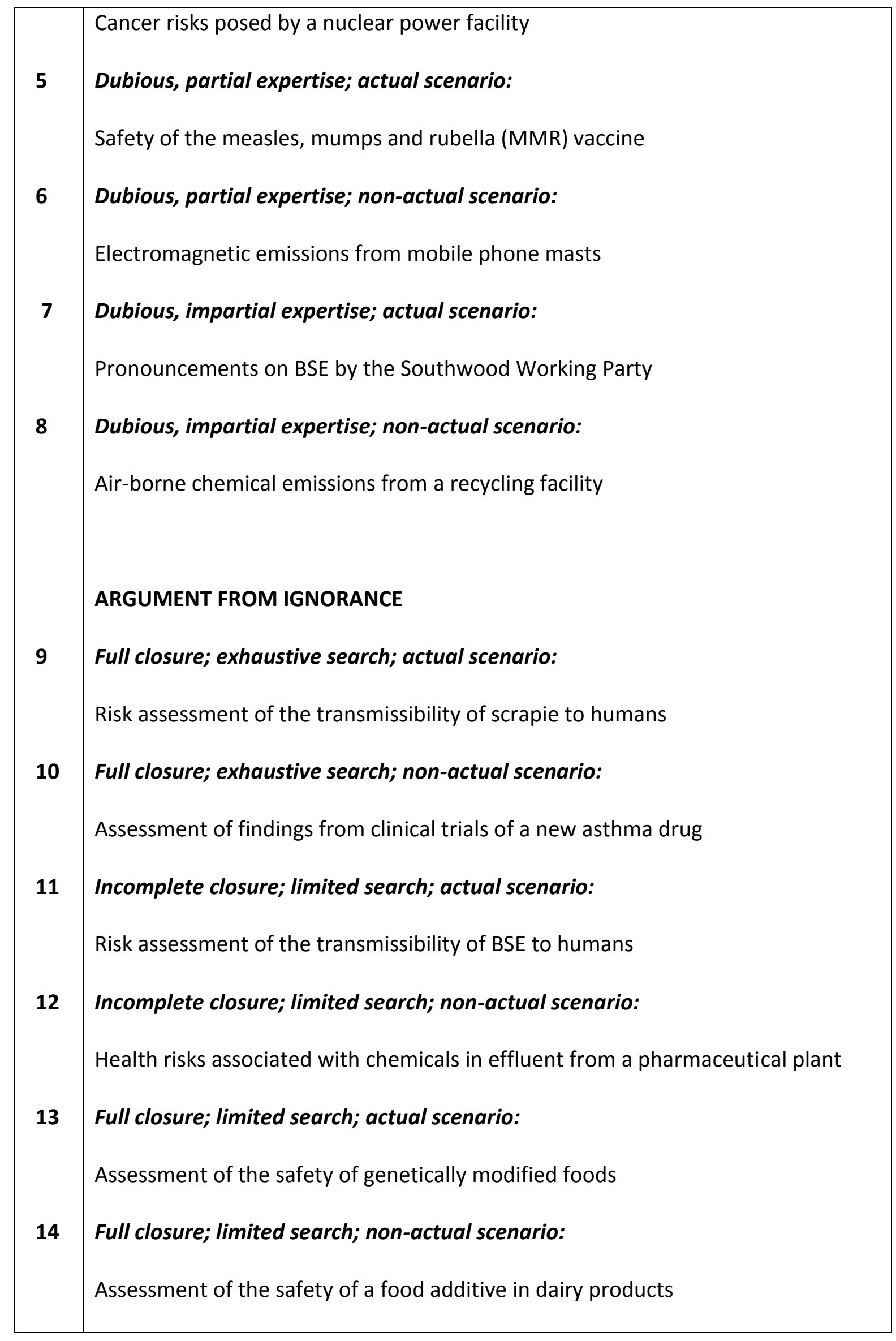




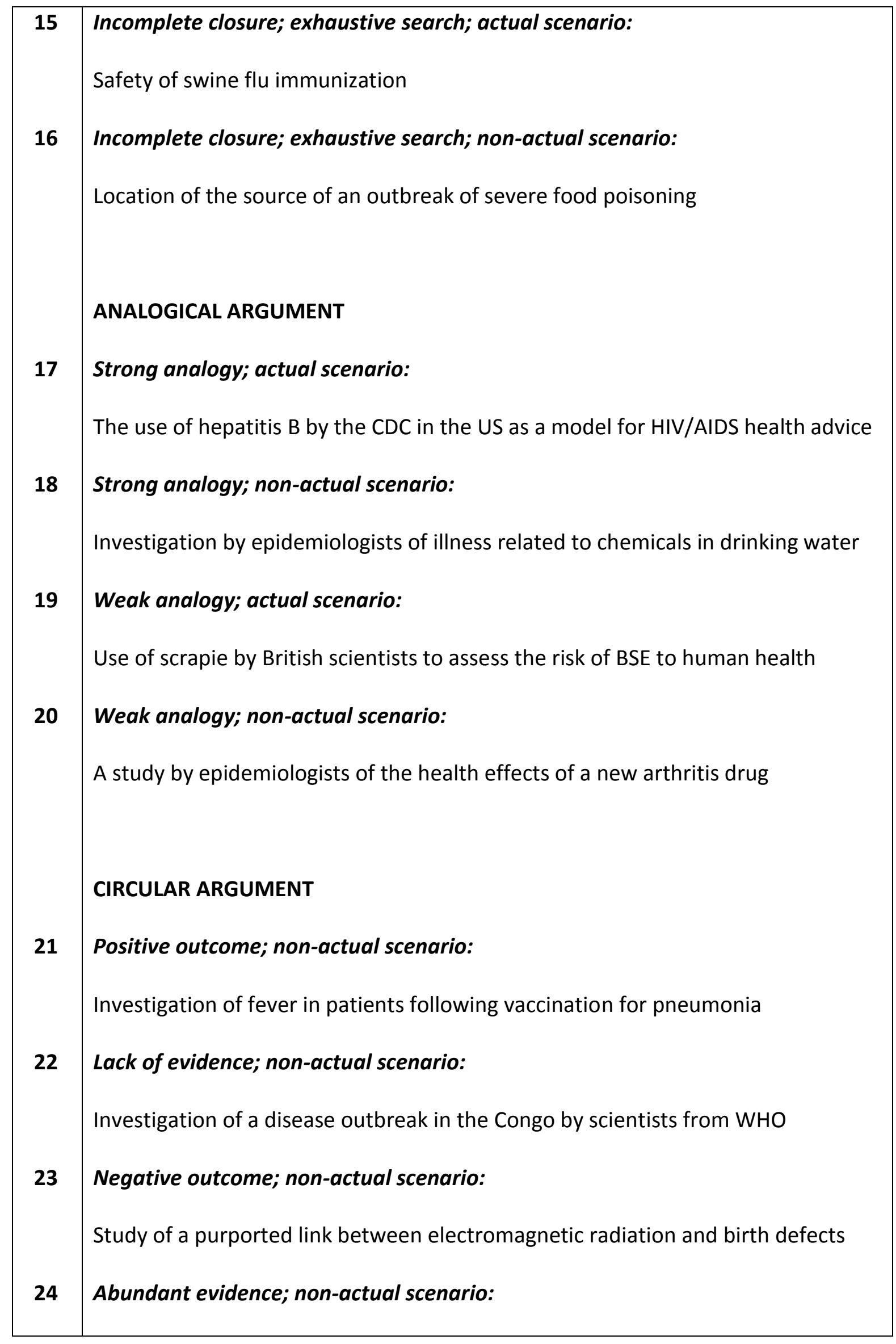


Table 2: Public health scenarios

\section{Acknowledgements}

The author acknowledges with gratitude the assistance of the following people and organizations in the recruitment of subjects for this study: Peter Homa (Chief Executive, Nottingham University Hospitals NHS Trust), Susan James (Chief Executive, The Royal Derby Hospital), Mark Lewis (Managing Director, John Lewis, Nottingham), Julie Bowley (General Manager, Roko health club, Nottingham), Simon Skelson (General Manager, David Lloyd health club, Nottingham). Special thanks go to Gavin Brookes (SPUR student, Nottingham Trent University), who played a key role in the formal recruitment activities undertaken as part of this study. The assistance of Dr Kevin Perrett (Consultant in Public Health Medicine, Manchester NHS) and Dr Vinod Tohani (formerly Consultant in Communicable Disease Control and Public Health Medicine, Southern Health and Social Services Board, Northern Ireland) is also gratefully acknowledged. The comments of two reviewers of this paper were particularly helpful and are gratefully acknowledged.

\section{Ethical approval}

Full ethical approval for this study was obtained from Nottingham Trent University, UK.

\section{Funding}

Funding for this study was provided by Nottingham Trent University, UK.

\section{Competing interests}

None declared. 


\section{REFERENCES}

1. Cummings L. Rethinking the BSE crisis: A study of scientific reasoning under uncertainty. Dordrecht: Springer; 2010.

2. Gigerenzer G, Brighton $\mathrm{H}$. Homo heuristicus: Why biased minds make better inferences. Topics in Cognitive Science 2009; 1: 107-43.

3. Walton D. Arguments from ignorance. University Park, PA: The Pennsylvania State University; 1996.

4. Walton DN. Why fallacies appear to be better arguments than they are. Informal Logic 2010; 30: 159-84.

5. Brown P, Cathala F, Raubertas RF, Gajdusek DC, Castaigne P. The epidemiology of Creutzfeldt-Jakob disease: Conclusion of a 15-year investigation in France and review of the world literature. Neurology 1987; 37: 895-904.

6. Cummings L. Informal fallacies as cognitive heuristics in public health reasoning. Informal Logic 2014; 34: to appear.

7. Bond M. Risk school. Nature 2009; 461: 1189-92. 